\title{
La Unión General de Trabajadores en Cantabria (1888-1917): Nacimiento y desarrollo de una estructura societaria*
}

\author{
Antonio Santoveña Seitén ${ }^{* *}$
}

\section{RESUMEN ABSTRACT}

Este artículo estudia la trayectoria histórica de la Unión General de Trabajadores en Cantabria entre agosto de 1888 (en que fue creada) y finales de 1917 (cuando, debido a la huelga general revolucionaria de ese año, quedó desmantelada temporalmente). Para ello, el texto se divide en tres partes: mientras la inicial coincide con el establecimiento de las primeras sociedades de resistencia en Santander, la segunda se centra en la expansión obrerista producida desde 1898 tanto en esta ciudad como en otras localidades de la región citada; por último, el tercer apartado analiza la evolución de las colectividades proletarias a partir de 1905.
This paper is the result of research into the historical evolution of the General Workers Union in Cantabria between August 1888 (in which it was founded) and the end of 1917 (when, due to the revolutionary general strike of that year, the organization was temporarily prohibited). For this purpose, the paper is divided into three parts. The first deals with the creation of the earliest trade union societies in Santander. The second is centred on the growth of the working-class movement from 1898 as in this city as in other localities in the same region. Lastly, the third examines the evolution of the proletarian societies since 1905.

* La realización de este artículo ha sido posible gracias a un convenio de colaboración entre la Universidad de Cantabria y la Unión General de Trabajadores.

** Doctor en Historia por la Universidad de Cantabria. Profesor de Historia Contemporánea en los Cursos de Español para Extranjeros de la Universidad Internacional Menéndez Pelayo (Santander). 


$\begin{aligned} \text { PALABRAS CLAVE } & \text { KEYWORDS } \\ \text { Movimiento obrero. Sindicalismo. } & \text { Working-class movement. Trade } \\ \text { Socialismo. Unión General de } & \text { unionism. Socialism. General Workers } \\ \text { Trabajadores. Catabria } & \text { Union. Cantabria. }\end{aligned}$

\section{GÉNESIS DEL MOVIMIENTO OBRERO CÁNTABRO}

En consonancia con otras zonas de España, los orígenes del asociacionismo obrero en Cantabria se remontan a la primera mitad del siglo XIX. Así, ya desde 1832 el proletariado montañés trató de suavizar las duras condiciones de vida a que estaba sometido mediante la fundación de diversas sociedades de socorros mutuos. Las mismas ofrecian, a cambio del pago de una cantidad de dinero en concepto de entrada y de una cuota periódica, un sistema de asistencia médica o médico-farmacéutica a sus miembros en caso de enfermedad o accidente laboral, además de un subsidio si la indisposición se prolongaba en el tiempo. A la vez, aunque era habitual que dichas entidades corrieran con los gastos del entierro cuando fallecía un socio, algunas también concedían ayudas a los familiares más directos del difunto ${ }^{1}$.

Este incipiente movimiento asociativo, desarrollado durante los años centrales de la mencionada centuria, iba a experimentar un avance cualitativo desde comienzos del último tercio de ella, cuando, aparte de producirse la aparición de nuevas sociedades de socorros mutuos en la región, empezaron a crearse algunas de carácter cooperativo. Semejantes entidades fueron concebidas con la finalidad de proporcionar a la clase obrera una alternativa al sistema socio-económico vigente que eludiese los vicios de éste. A tal efecto, expresaban en sus estatutos el propósito de abrir almacenes para la venta de comestibles, ropa, calzado y otros artículos de uso cotidiano; igualmente, solía ser intención de los promotores de estas iniciativas verificar cuantas acciones pidieran contribuir al bienestar de los cooperativistas ${ }^{2}$.

Coincidiendo con la situación descrita, debe señalarse asimismo la aparición en Santander desde 1870 de un grupúsculo vinculado a la Federa-

\footnotetext{
1 Esta fórmula de sociabilidad popular fue abierta en suelo cántabro con una organización llamada "Hermandad de Obra Prima».

2 Las primeras entidades de este tipo en Cantabria fueron la «Sociedad Cooperativa de Santander» (constituida en 1869), la «Asociación de Obreros de Santander» (documentada en 1870) y la «Asociación de obreros de Torrelavega» (también de 1870).
} 
ción Regional Española de la Asociación Internacional de Trabajadores. Este núcleo tenía como objetivo coadyuvar a la unión de todos los obreros del mundo en su anhelo por conseguir la regeneración socio-económica del proletariado. Para lograr esta meta, los internacionalistas contaban con un instrumento de lucha formidable: la huelga, a la que recurrían tantas veces como la consideraban oportuno. No obstante, tal forma de actuar iba a verse muy limitada debido a la represión gubernativa, en particular tras el golpe de Estado del general Pavía en 1874. Como consecuencia de ello, la repercusión del bakuninismo nunca sería relevante en la provincia analizada; por el contrario, puede decirse que siempre fue escasa ${ }^{3}$.

Pero, sin duda, el gran impulso cualitativo del movimiento obrero iba a registrarse desde 1883 , merced a la creación de la primera sociedad de resistencia propiamente dicha de Cantabria. Ocurrió que el 13 de marzo de ese año varios trabajadores de la capital montañesa acordaron constituir una asociación de índole defensiva bajo el nombre «Sociedad de Impresores, Litógrafos y Encuadernadores de Santander». Por voluntad explícita de sus fundadores, la entidad recién formada tenía como fin mejorar la situación moral y material de sus afiliados. Unos afiliados que, por cierto, podian militar en cualquier partido político, escuela de pensamiento 0 credo religioso, ya que, al carecer de objetivos ajenos al progreso obrero, la sociedad en cuestión permitía el ingreso en sus filas de cuantas personas pertenecientes al ramo de las artes gráficas lo deseasen, con el único requisito de que respetaran lo preceptuado en el reglamento de la misma ${ }^{4}$.

Tomando como punto de partida estas bases, la nueva fórmula de organización obrera aspiraba a encuadrar a todos los operarios de un mismo oficio y ámbito geográfico (en este caso, a los empleados de las imprentas santanderinas) con el fin de proteger sus intereses frente a los de sus patronos. Así, a través del pago de una cuota (50 céntimos de peseta a la semana), los afiliados podían disponer de un medio con el que presionar a los empresarios en las negociaciones entre ambas partes. Gracias a este procedimiento, que se fundamentaba en crear un fondo (o «caja de resistencia») con el que afrontar cualquier período de inactividad voluntaria causado por las arbitrariedades patronales, iba a empezar a hacerse realidad una antigua ilusión de los trabajadores: el establecimiento de acuer-

\footnotetext{
3 Ver La Solidaridad (Madrid), 16-VII y 3-IX-1870: así como La Federación (Barcelona), 21VIII-1870.

4 Ver Sociedad de Impresores. Litógrafos y Encuadernadores. Reglamento, Imprenta de La Voz Montañesa, Santander, 1886, pág. 5; así como Boletín de la Sociedad de Impresores, Litógrafos y Encuadernadores de Santander (Santander), 30-X-1886 y 30-IV-1887.
} 
dos colectivos que sustituyesen a los tradicionales de tipo individual, en los que la debilidad del asalariado ante su patrono facilitaba la imposición de unas condiciones abusivas de éste sobre aquél.

La novedosa línea de actuación introducida en Cantabria por la asociación de operarios de las artes gráficas no debió de ser demasiado convincente, sin embargo, en un principio para muchos de sus destinatarios potenciales. Ésta es la conclusión que cabe extraer del hecho de que la consabida entidad, luego de atravesar algunas dificultades, hubo de ser reorganizada en marzo de 1885. Ahora bien, en su segunda etapa, la Sociedad de impresores iba a adquirir el suficiente grado de solidez (o, al menos, así lo debieron entender sus responsables) como para decidir, en febrero de 1886, su ingreso en la Federación Tipográfica Española (que, a su vez, había sido creada en 1882). De este modo, lo que había comenzado siendo una iniciativa a escala local, pasaba a convertirse en parte de un proyecto más extenso y ambicioso que pretendía defender los intereses de todos los trabajadores del mismo oficio en España ${ }^{5}$.

La ampliación del marco territorial dentro del que ejercía sus actividades una sociedad de resistencia radicada en Santander iba a alcanzar una dimensión aún mayor desde 1888. En efecto, entre los días 12 y 15 de agosto del referido año se celebró en Barcelona un congreso nacional obrero en el curso del cual tuvo lugar la fundación de la Unión General de Trabajadores (UGT). A pesar de que en ese acontecimiento no hubo presencia física de representantes montañeses, quedó constancia del envío de uria carta de adhesión por parte de los dirigentes de una entidad que, denominada "Sociedad de Ebanistas, Silleros, Tallistas y Torneros de Santander», se había constituido el 11 de diciembre de 1887, siguiendo las pautas delineadas por los impresores, litógrafos y encuadernadores. Por ello, puede decirse que el movimiento obrero cántabro participó desde sus inicios en el designio de crear una gran organización que llegara a aglutinar algún día al conjunto del proletariado español ${ }^{6}$.

Con todo, las directrices de esta forma trazadas muy pronto iban a verse constreñidas por el exiguo nivel de desarrollo que hasta ese instan-

5 La Sociedad de Impresores de Santander debió de contar siempre con un número muy pequeño de afiliados. Ejemplo de ello son los 33 miembros que poseía en septiembre de 1886, los 49 de diciembre de ese año, los 56 de marzo de 1887, los 48 de junio o los 41 de diciembre del mismo año. Por esa época, la asociación tuvo su domicilio en el piso principal del número 17 de la calle de Cervantes (Boletín de la Sociedad de Impresores. Litógrafos y Encuadernadores de Santander, 30-X-1886, 13-I y 30-IV-1887; así como La Unión Tipográfica (Madrid), 18-VIII-1887 y 23 (I-1888).

6 El Socialista (Madrid), 30-XII-1887 y 24-VIII-1888. 
te había adquirido el obrerismo hispano en general y el montañés en particular. Sucedía que, en esta época, las sociedades de resistencia a menudo sólo eran agrupaciones coyunturales de operarios de un mismo oficio que se unían para defender sus intereses de manera coordinada ante un problema o una reivindicación laboral en concreto. Una vez que se solventaba tal situación, ya fuese de modo satisfactorio o no, era frecuente que muchos asalariados dejaran de cotizar a la asociación a la que pertenecían, con el perjuicio correspondiente para la subsistencia de ésta, que podía incluso desaparecer. Así ocurrió tanto con la entidad que velaba por los trabajadores en madera de Santander como con la que acogía a los empleados gráficos de dicha ciudad, que se había disuelto en mayo de 1888.

Las limitaciones evidenciadas por el asociacionismo obrero cántabro durante los años ochenta iban a empezar a ser superadas desde comienzos de la década siguiente. A ello contribuyó en gran medida la notable revitalización anímica experimentada por el proletariado universal desde el 1 de mayo de 1890 con motivo de la instauración de la que se llamaría «Fiesta del Trabajo» ${ }^{7}$. En este sentido cabe señalar cómo los actos realizados en Santander favorecieron la reorganización de la Sociedad de Impresores el 14 de diciembre, así como su incorporación, ya a principios de 1891, a la UGT ${ }^{8}$.

Mayor dinamismo asociativo iba a suscitar aún la celebración de mayo de 1891. Y es que la misma impulsó el nacimiento de seis nuevas sociedades de resistencia en Santander, que estuvieron integradas por trabajadores en madera, albañiles, pintores, toneleros, constructores de calzado y jornaleros del muelle. En medio de este ambiente expansivo, los responsables de las distintas entidades se convencieron de las ventajas que podía proporcionar una acción conjunta. Por esta causa, además de tomar en alquiler el primer piso del número 15 de la calle del Río de la Pila para utilizarlo como domicilio común, casi todas las colectividades obreras fueron ingresando en la UGT entre los meses finales de aquel año y los iniciales del subsecuente ${ }^{9}$.

\footnotetext{
7 Con el fin de hacer la recaer en domingo, dicha fiesta fue pospuesta en muchos lugares de España, entre ellos Santander, al día 4 (Ibid., 9-V-1890).

8 Sociedad de Impresores. Litógrafos y Encuadernadores. Reglamento, Imp. y Lit. Francisco Fons. Santander, 1891, passim.

9 El Socialista, 26-VI, 23-X, 13 y 20-XI, 18-XII-1891, así como 4-III-1892. Ver también las actas de las sesiones celebradas por el Comité Nacional de la UGT los días 6 de octubre y 15 de diciembre de 1891, amén del 5 de enero de 1892 reproducidas en Actas de la Unión General de Trabajadores de España, vol. 1, 1888-1892. Grijalbo, Barcelona, 1977, págs. 184, 193, 196 y 197).
} 
La labor desplegada por algunas de las sociedades citadas iba a reflejarse en la declaración de varias huelgas. Al margen de dos llevadas a cabo en junio de 1891 por los empleados de otras tantas imprentas de la capital montañesa ( $y$ que terminaron de manera desfavorable para los mismos), hay que destacar la planteada en mayo de 1892 por los jornaleros del muelle. Este conflicto, originado por el deseo de lograr una elevación en las tarifas de carga y descarga de buques, se acabaría solucionando con el triunfo de los huelguistas tras ocho días de paralización del puerto santanderino ${ }^{10}$.

El éxito alcanzado por el obrerismo en este conflicto, unido a la actividad propagandística desarrollada durante las semanas anteriores por Pablo Iglesias, iban a significar un gran estímulo para el movimiento asociativo en Cantabria. Fruto de ello fue la fundación de algunas sociedades en Santander (caso de la formada por los sastres, la de los trabajadores en hierro o la promovida por los canteros) y, en especial, un incremento en la cifra de afiliados de las ya existentes. Como complemento a estos avances, todas las entidades que componían el Centro Obrero de la ciudad acordaron vincular éste en bloque a la UGT ${ }^{11}$.

En este contexto, los dirigentes de la mayor parte de las colectividades empezaron a sentir la necesidad de disponer de unas instalaciones más adecuadas que las de la calle del Río de la Pila. Después de diversas gestiones, el anhelo societario en lo relativo a tener un domicilio digno iba a quedar satisfecho con su establecimiento en un edificio en el que había radicado la primera logia masónica de Santander, que lo cedió en alquiler con la totalidad de sus enseres. Este inmueble, sito en el número 12 de la calle de las Animas (actualmente Alcázar de Toledo, número 14), sería desde su inauguración el 30 de abril de 1893 punto de encuentro para el proletariado, ya que, aparte de acoger a las sociedades obreras y a la Agrupación Socialista Local (que databa de mayo de 1887), fue concebido también como un lugar de recreo e instrucción donde los asalariados podían pasar sus escasas horas de ocio alejados de los peligros inherentes a las tabernas ${ }^{12}$.

10 Cfr. El Correo de Cantabria (Santander), 23 a 27-V-1892; La Publicidad (Santander), 23 a 30-V-1892. El Atlántico (Santander), 24 a 31-V-1892; El Aviso (Santander), 24 a 31-V-1892; así como Archivo de la Cámara oficial de Comercios, Industria y Navegación de Cantabria (Santander), legajo 31 , carpeta 445.

El Socialista, 21-X-1892.

12 La Lucha Obrera (Santander), 30-IV y 7-V-1893; El Socialista, 19-V-1893, y Fundación Pablo lglesias (Madrid). AA.VV.- ABA 153-10, Ramos, Antonio, "Movimiento socialista y obrero en Santander y su provincia» (mecanografiado sin fecha). 
Así las cosas, en agosto de 1893 el Centro Obrero santanderino contaba con 960 miembros que se repartían entre nueve sociedades, todas afectas a la macroorganización ugetista. En orden decreciente de integrantes, tales entidades eran las de jornaleros del muelle (con 624 componentes), panaderos (72), operarios en hierro y demás metales (17), constructores de calzado (48), trabajadores en madera y tapiceros (44), albañiles (36), tipógrafos (33), pintores (120) y canteros (12) ${ }^{13}$.

Pese a que la cantidad de federados todavía era pequeña y a que la mayoría de ellos pertenecía a una sola sección (la de cargadores del mueIle, que concentraba a dos de cada tres afiliados), lo cierto es que la magnitud del movimiento obrero de la capital cántabra era estimable respecto al del resto de España. Prueba de esta circunstancia es que, en aquel momento, los efectivos adscritos en dicha ciudad a la UGT representaban el $11,2 \%$ de los que ésta poseía para el conjunto del país, si bien debe subrayarse que la implantación de la misma se limitaba por entonces únicamente a 26 poblaciones del Estado ${ }^{14}$.

La situación de moderado progreso en que se hallaba el obrerismo montañés desde comienzos de la década de los noventa iba a interrumpirse en 1894. Ese año se empezó a percibir un proceso de decadencia que terminaría causando la desaparición de todas las sociedades de resistencia de Santander, salvo la de impresores y la de zapateros. Tal fenómeno, análogo al que estaba ocurriendo en otras zonas de España, fue atribuido por los coetáneos a las repercusiones negativas de la crisis económica que afectaba al país. En estas condiciones, habría que aguardar a la peculiar coyuntura suscitada a finales del decenio ( $y$, por extensión, del siglo) para poder observar una recuperación del movimiento asociativo ${ }^{15}$.

\section{PERIOODO DE EXPANSIÓN SOCIETARIA}

La derrota militar sufrida por España ante Estados Unidos en 1898, además de traer consigo la pérdida de nuestras últimas colonias ultramarinas, produjo una crisis de identidad colectiva en territorio hispano. Ello fue así porque, junto a sus enormes costes materiales y humanos, el mencionado fracaso dejó al descubierto las debilidades del orden socio-políti-

\footnotetext{
13 El Socialista, 6-X-1893.

${ }_{14}$ En el mes indicado la UGT se componía de 97 sociedades y 8.553 individuos (Ibid.).

15 ACEVEDO, Isidoro, «El movimiento obrero en Santander», en La Voz del Pueblo (Santander), 6-VI-1903.
} 
co vigente. En esta situación iban a gestarse varias reflexiones acerca de los problemas nacionales y el modo de resolverlos. Entre esas iniciativas cabe destacar las de algunos escritores y pensadores, la promovida por la burguesía catalana o la auspiciada por las formaciones obreras, que experimentaron un notable resurgir en el tránsito intersecular.

Esta revitalización del obrerismo, a la que fue ajena el proletariado cántabro, se iba a concretar en una campaña de organización y propaganda. Como es lógico, la misma tuvo su foco santanderino en las excelentes instalaciones de la calle de las Ánimas. Es más, dicha campaña se vio también muy favorecida por la publicación desde 1898 del semanario La Voz del Pueblo. Este periódico, concebido como un instrumento al servicio de la clase trabajadora, pronto se convirtió en exponente eficaz de sus designios políticos y económicos. Hasta tal extremo fue así, que se puede considerar al referido medio de comunicación reflejo y, a la vez, fundamento del desarrollo que iba a alcanzar el asociacionismo en Cantabria a partir de aquel instante ${ }^{16}$.

Debido a los factores señalados (rebrote del espíritu societario, protagonismo del Centro Obrero y existencia de un canal de difusión impreso) desde principios de 1899 iba a registrarse una gran actividad asociativa. Testimonio fidedigno de su magnitud ofrece la reorganización o puesta en marcha a lo largo de los dos años y medio siguientes de más de 20 entidades de resistencia en Santander, muchas de las cuales se incorporaron a la UGT.

Amén de compartir un sentido eminentemente defensivo, todas estas colectividades respondían a una estructura muy similar. La misma disponía de tres órganos de gobierno y decisión esenciales. Primero, una junta directiva, que era la encargada de administrar los intereses de la sociedad; configurada por un presidente, un vicepresidente, uno o dos secretarios, un contador, un tesorero y un número variable de vocales, se reunía con carácter ordinario cada cierto tiempo (una vez por semana, quincena o mes) y de modo extraordinario siempre que fuese preciso. En segundo término, una comisión revisora, que tenía como tarea examinar las cuentas de la entidad, constando de 3 ó 5 individuos. Por último, una junta general, en la que radicaba la soberanía de la asociación; solía celebrarse dos o

16 Desde su aparición el 19 de junio de 1898 hasta el último número, publicado el 30 de diciembre de 1905. La Voz del Pueblo contó con la colaboración de los principales dirigentes obreros locales; también reprodujo textos de autores como Pablo iglesias, Antonio García Quejido, Juan José Morato, Vicente Barrio, Miguel de Unamuno, Jaime Vera, Friedrich Engels, Jules Guesde, Jean Jaurés, Paul Lafargue, Víctor Hugo o Emile Zola, por mencionar sólo algunos. 
cuatro veces al año (esto es, una por semestre o una por trimestre), así como cuando la junta directiva o cierta cantidad de miembros lo solicitaban. En cualquiera de los casos, era obligatoria la asistencia de todos los socios, quienes, por su parte, gozaban del derecho a presentar cuantas proposiciones quisieran y a elegir a los componentes de la junta directiva.

La amplitud adquirida por el movimiento obrero en la capital montañesa coincidiendo con el cambio de siglo iba a influir sobre las condiciones laborales de la población asalariada. Al margen de las demandas de índole general formuladas un año tras otro con motivo de los festejos del 1 de mayo (jornada de ocho horas y retribución justa), cada sociedad de defensa utilizó en esa época la táctica de enviar un escrito razonado a todos los patronos de su oficio detallando algunas mejoras que reivindicaba para los trabajadores. Luego de conceder un lapso de tiempo a fin de que los empresarios pudieran estudiar las aspiraciones que les planteaban, los responsables societarios valoraban las respuestas recibidas o, en su defecto, la ausencia de éstas ${ }^{17}$.

De acuerdo con este procedimiento, iba a ser frecuente la consecución de logros importantes para sus afiliados por parte de las sociedades que venimos analizando. Buena muestra de ello dan, por ejemplo, las subidas salariales y/o disminuciones en la duración de la jornada obtenidas por las colectividades de constructores de carruajes, albañiles, metalúrgicos, canteros y marmolistas, zapateros y empleados de las fábricas de mosaicos. Aunque tales avances todavía estaban lejos de los objetivos ideales anhelados por el proletariado, se puede decir que contribuyeron en grado apreciable a hacer más llevadera su situación socio-económica a los trabajadores de Cantabria ${ }^{18}$.

Sin embargo, también podía ocurrir ( $y$, de hecho, así sucedió en muchas ocasiones) que las respuestas patronales no gustasen a los líderes obreros o que, sencillamente, ni siquiera llegaran a producirse. En esas circunstancias, las sociedades sopesaban las posibilidades de éxito que

17 Esta modalidad reivindicativa, consistente en exponer de forma respetuosa algunas peticiones modestas, tenía, a juicio de Pablo Iglesias, la ventaja de no suscitar demasiado rechazo entre los patronos, compensándose la limitada magnitud de sus progresos con la realización de varias reclamaciones sucesivas, de manera que pudieran alcanzarse gradualmente unas mejoras que, si se solicitaban de una sola vez, apenas contaban con posibilidades de prosperar. (lGLEsIAS. Pablo, Las organizaciones de resistencia, Imp. Lit. y Enc. Vda. de F. Fons, Santander, 1902, págs. 8-9).

18 Ver La Voz del Pueblo, 4, 11 y 25-V; 1, 15 y 22-VI, así como 13-VII-1901. Igualmente pueden consultarse las actas de las sesiones celebradas por el Comité Nacional de la UGT los días 18 y 25 de julio de 1901 (reproducidas en Actas de la Unión General de Trabajadores de España. vol. 2, 1899-1904, en Estudios de Historia Social, números 8-9 (enero-junio 1979), págs. 390 y 391). 
tenían si tomaban la resolución de declararse en huelga. Cuando las expectativas eran escasas sólo quedaba la opción de aguardar una coyuntura más propicia. Por el contrario, en el supuesto de haber esperanzas de triunfo lo normal era que se planteara el conflicto; una vez iniciado éste por un grupo de trabajadores, iba a ser decisivo el apoyo moral y económico que pudiera prestar la asociación defensiva correspondiente, hasta el punto de que, a menudo, el desenlace de este tipo de confrontaciones estaba condicionado en gran medida por la solidez de la entidad implicada.

Partiendo de estas premisas, es fácil comprender cómo el auge societario de finales del siglo $x \mathrm{IX}$ y comienzos del $\mathrm{xx}$ iba a inaugurar el período de mayor conflictividad laboral hasta entonces conocido en la capital cántabra. Entre la larga serie de huelgas que tuvieron lugar en esos años y concluyeron de manera favorable a los asalariados destacaron (bien sea por el número de participantes, duración o forma de resolverse) la sostenida por los varios cientos de hombres, mujeres y niños que intervenían en la construcción de los futuros altos hornos de Nueva Montaña (marzo de 1900), la que protagonizaron durante cinco meses los canteros que trabajaban para el contratista Serafín Llama en la Alameda Primera (marzo a agosto de 1900), así como la declarada por los operarios de los talleres metalúrgicos de Corcho Hijos, en la que, curiosamente, actuó como mediadora una comisión compuesta por presidentes de diversas asociaciones pertenecientes al Centro Obrero (mayo a julio de 1901) ${ }^{19}$.

A pesar de que, como ya se ha indicado, las distintas sociedades procuraban evitar la huelga si no advertían alguna posibilidad de victoria, lo cierto es que las mismas acabaron sufriendo varias derrotas imprevistas. Con todo, la moderación y prudencia que casi siempre mostraron los responsables obreros iban a proporcionar buenos resultados a sus organizaciones tanto a través de la reclamación o negociación pacífica como mediante el recurso extremo al conflicto. Impelido por los beneficios derivados de este modo de proceder, y deseoso de consolidar su posición, el obrerismo montañés iba a sentir la necesidad de dotarse de una estructura aún más compleja.

Los esfuerzos desarrollados con este propósito iban a culminar del 7 al 9 de agosto de 1901, días entre los que se celebró el congreso fundacional de la llamada "Federación Local de Sociedades Obreras". Este organismo, creado por voluntad de unos 3.000 trabajadores encuadrados en 13

19 Noticiero Santanderino (Santander), 9 y 10-Ill-1900: El Cantábrico (Santander), 10 a 12-lil1900; así como La Voz del Pueblo, 31-III,1-IX-1900, 1 y 29-VI, 6-VII-1901. 
secciones del Centro Obrero y en la Agrupación Socialista de Santander, adoptó desde su nacimiento tres acuerdos básicos. En primer término, ingresar colectivamente en la UGT a fin de dar la máxima proyección geográfica posible a sus actividades. Segundo, regular las competencias de un Comité Central que, entre otras cosas, había de decidir la pertinencia o no de convocar las huelgas. Por último, establecer la obligación de que, en caso de conflicto laboral, la Federación auxiliase a los huelguistas ${ }^{20}$.

Sobre estos postulados, el 2 de septiembre de 1901 empezó a funcionar la Federación Local santanderina. Los excelentes augurios suscitados entre los asalariados por la flamante organización se concretaron en la incorporación a la misma de varias sociedades más. Pero, con diferencia, el principal efecto iba a registrarse en la capacidad negociadora del proletariado. $Y$ es que, a partir de ese momento, los trabajadores pudieron disponer del instrumento de presión más poderoso que alguna vez habían conocido. Gracias a él, estuvieron en situación de forzar a bastantes patronos a que conviniesen con ellos las condiciones en que se debían verificar los procesos productivos. De esta suerte, la clase obrera iba a lograr mejoras (ya fuese por medio de pactos amistosos o huelgas) que vinieron a aumentar las obtenidas con anterioridad por las colectividades de oficio a título individual o integradas en el Centro Obrero.

Paralelamente a estas consecuciones, la Federación Local decidió promover diversas conferencias científico-culturales a fin de ampliar la formación de sus afiliados, amén de completar su cometido específico con la apertura de una sección de socorros mutuos denominada «La Fraternidad». Semejante dinamismo iba a coincidir con el período de mayor pujanza del movimiento obrero cántabro. Signos de ella fueron, aparte de numerosos conflictos laborales, la expansión del asociacionismo fuera de la capital con el nacimiento desde 1901 de varias sociedades de resistencia en Torrelavega, Castro Urdiales, El Astillero, Cabárceno, Mioño, Santoña, Heras, Obregón y Pámanes, la creación entre 1902 y 1903 de 11 nuevas entidades en Santander, el mantenimiento de un alto nivel de afiliación en esos años (que convirtió a la provincia que nos ocupa, con 23 secciones y 3.164 federados, en la quinta de España en militantes ugetistas) o el hecho

20 Las sociedades representadas en el congreso en que se constituyó la Federación Local (y su número de afiliados) fueron: obreros del muelle (770), carpinteros y ebanistas (503), obreros en hierro y demás metales (420), albañiles (392), canteros y marmolistas (300), constructores de calzado (200), impresores, litógrafos y encuadernadores (93), pintores (56), panaderos (50), constructores de carruajes (45), empleados de las fábricas de mosaicos y piedra artificial (40), peluqueros-barberos (40), curtidores (25), además de la Agrupación Socialista (98). (Ver La Voz del Pueblo, 10, 17, 24 y $31-$ VIII, 7 y 14-IX-1901). 
de que un líder del obrerismo montañés (Isidoro Rodríguez Acevedo) fuese elegido en mayo de 1902 para presidir la mesa de un congreso nacional de la UGT (circunstancia que se repetiría en 1905) ${ }^{21}$.

Ahora bien, el importante avance experimentado por la clase trabajadora en Cantabria durante los instantes finales del siglo XIX y principios del $x x$ no estuvo exento de dificultades. Así, poco después de fundarse la $\mathrm{Fe}-$ deración Local de Santander, varios empresarios de la ciudad resolvieron crear una sociedad de contrarresistencia, es decir, una organización concebida para aglutinar a los obreros bajo el auspicio de sus patronos. Los esfuerzos realizados en este sentido iban a acabar malográndose, sin embargo, debido tanto a la propia fortaleza de la estructura societaria erigida por el proletariado como a la renuencia de éste a encuadrarse en una entidad impulsada por personas ajenas a su extracción socio-económica ${ }^{22}$.

El fracaso de la tentativa patronal por anular los progresos del movimiento obrero dejó indemne, en cambio, a otra iniciativa hasta cierto punto similar. En efecto, ocurrió que los éxitos alcanzados por las asociaciones socialistas en el ámbito espacial que estamos estudiando propiciaron la aparición de un núcleo anarquista que iba a acometer una intensa actividad, orientada a facilitar el ingreso de algunos de sus adeptos en sociedades adscritas a la Federación Local para, desde dentro de ellas, promover su desvinculación respecto a ésta. Dicho plan conllevaba, además, como remate el acercamiento de las entidades segregadas a la causa libertaria $^{23}$.

No obstante, los exiguos resultados obtenidos a través de esta forma de proceder iban a poner de manifiesto la necesidad de recurrir a otra táctica. En este contexto, los anarquistas santanderinos determinaron fundar en julio de 1902 un organismo que, con el nombre «La Solidaridad Obrera», había de fomentar la creación de sociedades paralelas a las de la Federación Local. La !abor de la referida entidad iba a permitir, en los meses siguientes, la constitución de cuatro asociaciones, compuestas por zapateros, albañiles, pintores y carpinteros. A diferencia del tono moderado y negociador de las ugetistas, todas estas sociedades iban a signifi-

21 Ver La Voz del Pueblo, 8 y 22-11, 25-X-1902, así como El Socialista, 23- V-1902, 6-11-1903 y $26-V-1905$.

22 La Voz del Pueblo, 20-IX-1902: AceVEdo, I., «El movimiento...», loc. cit.; y Alonso [GonzÁLEZ], Bruno, El proletariado militante. Memorias de un provinciano. Tantín, Santander, 1994 [2. ${ }^{a}$ ed.], págs. 22-23.

${ }_{23}$ La Voz del Pueblo, 11-V-1901 y 20-IX-1902. 
carse por sus alegatos en favor de la huelga general y la propaganda por el hecho (esto es, el uso de la violencia) como medios de lucha ${ }^{24}$.

La rivalidad originada en el seno del obrerismo santanderino (y, sobremanera, en ciertos oficios) debido a la existencia de dos concepciones dispares sobre cómo defender los intereses de la clase asalariada repercutió negativamente en el estado de ésta. Prueba de ello es que, aprovechando las tensiones surgidas entre ambas corrientes y, por ende, su debilitamiento, varios patronos iban a estar en condiciones de revocar algunas de las mejoras logradas por sus empleados en los años anteriores. La cuestión se agravó cuando los anarquistas decidieron presionar en las empresas donde eran mayoría para que se despidiera a los operarios pertenecientes a la UGT. Así las cosas, cabe afirmar que el movimiento obrero entró desde 1903 en una fase de pugnas internas y estancamiento ${ }^{25}$.

Si bien estas circunstancias no pusieron en peligro de modo inmediato el grado de desarrollo alcanzado por el ugetismo montañés, la situación iba a variar desde 1904. Sucedió que, a los problemas ocasionados por las injerencias anarquistas, hubo que añadir a partir de entonces las consecuencias de una crisis de trabajo y de un fuerte encarecimiento de las subsistencias. Tales factores, unidos a la derrota sufrida ese mismo año por tres sociedades de Santander (jornaleros, jornaleras y carreteros del muelle) en la huelga que sostuvieron por solidaridad con los fogoneros y marineros de toda España, iban a afectar en gran medida a la Federación Local $^{26}$. De resultas de ello, ésta tuvo que soportar una disminución en la cifra de secciones y afiliados que la componían, al punto de circunscribirse en el mes de noviembre a 13 colectividades y poco más de 1.200 miembros ${ }^{27}$.

Este proceso de desintegración iba a culminar en 1905 por efecto de otra huelga saldada adversamente para los trabajadores. En esa oportunidad se trató de un conflicto promovido por los jornaleros del muelle san-

24 Adelante (Santander), 24-VIII-1902; La Voz del Pueblo, 15 y 22-XI, así como 6-XII-1902: y Acevedo, I., «El movimiento», loc. cit.

25 La Voz del Pueblo, 16-V-1903; y ACEVEDO, I., «El movimiento...», loc. cit.

26 Ver El Cantábrico, 8 a 31-1-1904: y La Voz del Pueblo, 9, 16 y 23-1, así como 6-11-1904.

27 Dichas entidades eran las de cargadores del muelle (que tenía 260 afiliados), carpinteros (181), canteros y marmolistas (180), camareros y cocineros (151), operarios de artes gráficas (105), moldeadores y modelistas (70), albañiles (43), panaderos (43), peluqueros y barberos (42), metalúrgicos (37), obreros del gas y electricidad (37), aserradores mecánicos (35) y curtidores (de los que se ignora su número exacto de efectivos para la fecha considerada); fuera de la Federación Local (y, por tanto, de la UGT) permanecían las de conserveras (con 250 componentes) y lateros (70). (INSTITUTO DE REFORMAS SOCIALES, Estadística de la Asociación obrera en $1{ }^{\circ}$ de noviembre de 1904. Imprenta de la sucesora de M. Minuesa de los Ríos, Madrid. 1907, pág. 197). 
tanderino, quienes, pese a contar con el apoyo de cargadores, aserradores mecánicos y algunos operarios de la construcción, hubieron de presenciar no sólo la frustración de sus demandas, sino también el desprestigio de la sociedad que velaba por ellos. Es más, la puesta en entredicho de la entidad que había sido el núcleo básico de la Federación Local durante muchos años incidió de tal forma, sobre este organismo, que acabó comportando la desaparición de bastantes secciones del mismo ${ }^{28}$.

\section{EL LARGO CAMINO DE LA RECUPERACIÓN}

Desarticulado en su estructura principal y sometido a los rigores de una coyuntura negativa, el movimiento obrero de la capital cántabra iba a verse abocado desde mediados de 1905 a una etapa de precariedad. Reflejo de ese estado es que, cuando los comités nacionales de la UGT y del PSOE convocaron un paro general de 24 horas en todo el país para el 20 de julio de aquel año como protesta por la incapacidad gubernamental frente a la escasez de trabajo y a la carestía de la vida, las pocas sociedades de resistencia que subsistían en la ciudad acordaron (en contraste con las de El Astillero, Cabárceno y Obregón) no secundarlo debido al difícil momento en que se hallaban; en su lugar, se limitaron a enviar un escrito de adhesión a los promotores de la jornada de paro ${ }^{29}$.

Por añadidura, la tendencia regresiva iniciada en Santander pronto se iba a propagar a los restantes enclaves obreros de la región. Este fenómeno produjo una merma notable en el número y tamaño de las colectividades, como lo atestigua el hecho de que, habiendo quedado reducida la UGT a 12 secciones y 581 afiliados para toda Cantabria en marzo de 1906, su volumen aún decrecería en recuentos posteriores. hasta situarse por debajo del medio millar de federados por espacio de varios años ${ }^{30}$.

El fuerte retroceso experimentado por el obrerismo montañés iba a impeler a sus responsables a buscar soluciones con las que corregir seme-

28 Ver La Voz del Pueblo, 1, 8 y 15-VII-1905; Los Rayos X (Santander), 8 y 15-VII-1905; así como El Ideal Cántabro (Santander), 9-VII-1905.

29 Ver La Voz del Pueblo, 22 y 29-VII-1905; El Socialista, 28-VII, 4 y 11-VIII, así como 8-IX1905.

30 La evolución de la cifra de afilíados a la UGT en suelo cántabro fue la siguiente: 530 en abril de 1907, 453 en septiembre de 1907, 385 en marzo de 1908, 368 en octubre de 1908 y 468 en marzo de 1909. (El Socialista, 6-IV-1906, 10-V y 18-X-1907, 27-lII y 23-X-1908, así como 23-IV1909). 
jante decadencia. Después de plantearse diversas alternativas, optaron por dar un mayor protagonismo a un cuadro dramático que se había creado en 1904. Con este propósito, la Federación Local de la capital decidió establecer un pequeño teatro en el primer piso de su sede de la calle de las Animas. Gracias a la nueva instalación, construida según los cánones del estilo modernista e inaugurada el 18 de febrero de 1906, la llamada "Sección Artística» (que estaba formada por hombres y mujeres vinculados a las distintas sociedades de defensa) iba a erigirse durante años en la colectividad más popular del Centro Obrero, disponiendo de un repertorio en el que se combinaban dramas, obras de temática social y juguetes cómicos ${ }^{31}$.

A través de estos elementos, los dirigentes societarios de Santander perseguían cuatro metas esenciales. Primero, volver a convertir el edificio de la calle de las Ánimas en un referente constante para la clase trabajadora. En segundo lugar, poner al alcance de ésta una forma de entretenimiento culta y sana, que apartase a sus integrantes de diversiones poco recomendables. Un tercer designio consistía en aprovechar las posibilidades que ofrece el teatro para difundir entre los obreros y sus familias ciertos contenidos ideológicos. Y, por último, se trataba de recaudar fondos con los que cubrir no sólo los gastos inherentes a las representaciones que se llevasen a cabo (adquisición de vestuario, muebles u objetos), sino también algunos de los originados por el funcionamiento ordinario de la Federación Local (alquiler de sede social, socorro de huelga, ayuda a compañeros necesitados, etcétera).

La buena acogida dispensada por el proletariado cántabro a la Sección Artística no iba a ser suficiente, sin embargo, para generar a corto plazo un avance en el movimiento asociativo. Por el contrario, éste continuó sumido en un clima de atonía que se manifestaba tanto en una escasa actividad societaria como en un exiguo nivel de conflictividad laboral. Dicho panorama sólo se vio alterado esporádicamente por la fundación de alguna entidad de resistencia y, en especial, por la huelga que sostu-

31 En la nómina de autores (y títulos) cabe destacar a Vital Aza (Francfort). Leopoldo Cano (La pasionaria). Sinesio Delgado (La obra), Joaquín Dicenta (Juan José, Aurora, El suicidio de Werther, El señor feudal y La confesión). Miguel Echegaray (Los hugonotes), Paolo Giacometti (La muerte civil). José Estremera (La cuerda floja), Ángel Guimerá (Tierra baja), Ignacio Iglesias (Juventud), Calixto Navarro (Salón Eslava), Pablo Parellada (El himno de Riego), Miguel Ramos Carrión (La careta verde), Santiago Rusiñol (El místico y Buena gente) o Eduardo Torralva Beci (Astrea, Justicia, Salvaje, En servicio de Dios y Hogar). (Cfr. La Voz de] Pueblo, 29-X-1904; El Cantábrico, 14, 18 y 19-Il-1906; amén de RADO, Eduardo, "A propósito de monaguillos. Cómo y por qué se fundó el Cuadro Artístico Socialista", ibid., 1-V-1928). 
vieron más de 10.000 mineros de la región entre agosto y septiembre de 1906 en solidaridad con sus compañeros vizcaínos, y que terminó con un triunfo aparente de los asalariados ${ }^{32}$.

En cualquier caso, lo cierto es que el ugetismo montañés iba a seguir inmerso en una crisis que mantenía a los trabajadores en una situación de vulnerabilidad. Habría que aguardar al año 1909 para que el ambiente suscitado a raíz de los sucesos de la denominada "Semana Trágica" (registrados entre el 26 de julio y el 1 de agosto) marcara un punto de inflexión en esta dinámica. $Y$ es que la indignación surgida en toda España a consecuencia de las medidas represivas tomadas por el Gobierno que encabezaba el conservador Antonio Maura, además de propiciar una alianza de los partidos políticos más avanzados en la "Conjunción Republicano Socialista", estimuló un rebrote del espíritu obrerista.

Efecto de este estado de cosas iba a ser la constitución, desde 1910, de numerosas sociedades de defensa en todo el país. Aunque tal efervescencia societaria (que en Cantabria se concretó en poblaciones como Santander, Camargo, Torrelavega, Obregón, El Astillero, Guarnizo, BooMaliaño, Peñacastillo, Liaño, Santoña o Cabárceno) no estuvo acompañada siempre por el ingreso de las nuevas entidades en la UGT, esta circunstancia en absoluto supuso una pérdida de protagonismo en territorio montañés para la macroorganización que presidía Pablo iglesias, ya que aquéllas quedaron dentro del área de influencia de la misma merced al gran ascendiente ejercido por la Federación Local santanderina.

Obviamente, el apreciable desarrollo que estaba alcanzando el movimiento obrero en la región que nos ocupa iba a conllevar un aumento importante de la actividad propagandística, que a lo largo de los años siguientes se materializaría en la convocatoria de multitud de mítines y conferencias. De igual modo. el renacer societario también desencadenó un incremento de la conflictividad laboral; fruto de él fue la declaración de bastantes huelgas que, motivadas en la mayoría de los casos por razones de retribución, horario, despido, seguridad o trato a los asalariados. acabaron, por lo general, con el triunfo de éstos. Mención aparte, por su valor simbólico, merece otro hecho acaecido durante ese período: la adopción de la denominación oficial de «Primero de Mayo» para designar a la calle que hasta entonces se había liamado «de las Ánimas»; este cambio, aprobado por el Ayuntamiento de Santander el 3 de mayo de 1911, tendría

32 El tiempo se encargaría de demostrar que, en realidad, fue una derrota. [Ver La Montaña (Santander), 21-VIII a 6-IX-1906; El Cantábrico, 22-VIII a 6-IX-1906; El Socialista, 7-|X-1906; y EI Trommel (El Astillero), 15-IX-1906.] 
plena vigencia el 8 de julio de aquel año, fecha en que fueron colocadas las nuevas placas ${ }^{33}$.

En medio de estos signos de vitalidad, el obrerismo cántabro iba a considerar la posibilidad de ampliar su campo habitual de actuación facilitando al proletariado la adquisición de alguno de sus alimentos básicos en las mejores condiciones de precio, calidad y peso. Para ello, la Federación Local de Santander creó una cooperativa productora de pan que, con el nombre «La Equidad» y domicilio social en el Centro Obrero de la calle del Primero de Mayo, fue inscrita en el Registro General de Asociaciones el 2 de marzo de 1912. Pocos días después empezó a funcionar su tahona, instalada en el número 12 de la calle de San Pedro. Esta industria pronto cobraría un auge estimable, como lo demuestra el hecho de que sus responsables decidieran comprar en 1913 el referido inmueble por 40.000 pesetas, pagaderas en 20 plazos anuales de 2.000 pesetas con un interés del $4 \%{ }^{34}$.

La incidencia de estos progresos iba a quedar diluida, sin embargo, en el clima de conmoción ocasionado por el estallido, en julio de 1914, de la que sería I Guerra Mundial. Es más, si bien España no participó en esa contienda bélica, sufriría hondos desajustes económicos derivados de ella. Estas alteraciones se pusieron de relieve sobre todo en aquellos ámbitos productivos que estaban más orientados al mercado exterior. Así, en el caso de Cantabria, ta.l circunstancia fue especialmente intensa tanto en la minería como en el tráfico portuarío. que experimentaron una contracción debido a la cual, a su vez, tuvo lugar un aumento del paro. A este infortunio hubo que añadir, además, una subida en el precio de los artículos de primera necesidad ${ }^{35}$.

Afectado por esta coyuntura desfavorable, el asociacionismo montañés iba a entrar en una nueva fase de declive. La misma se manifestaría durante los meses ulteriores no sólo en un retroceso de la cantidad de entidades de defensa y afiliados, sino también en una merma de la actividad desplegada por ellas. De esta forma, la dinámica societaria se șituaba dentro del marco geográfico analizado en unos parámetros que

33 Ver Archivo Municipal de Santander, legajo 1.556. documento número 17; y «Libro de actas municipales», número 2.333, folios 95 y 132: así como El Cantábrico, 8 y 9-VII-1911.

34 La República (Santander), 24-II, 9-III y 18-V-1912; El Cantábrico, 9 y 10-III-1912, 16-VII y 14-XI-1913; El Reformista (Santander), 22-II-1913; La Región Cántabra (Santander), 25-II-1916; Archivo del Gobierno de Cantabria (Santander), "Registro General de Asociaciones», libro l; y Fundación Francisco Largo Caballero (Madrid), "Documentación sobre la reclamación del patrimonio sindical de Cantabria».

35 Ver, a modo de ejemplo, La Región Cántabra, 25-VIII-1914; y El Cantábríco, 26-IX-1914. 
parecían estar reproduciendo el proceso de descomposición operado una década antes ${ }^{36}$.

No obstante, a medida que revestía mayor intensidad esta regresión iba a generalizarse entre los dirigentes obreros el convencimiento de que era preciso interrumpir dicha tendencia. A ello coadyuvó la propia agudización de los problemas de paro y carestía de las subsistencias que venía originando la guerra. Por esta causa, desde finales de 1916 los elementos más activos del proletariado cántabro concentraron sus energías en la tarea de constituir diversas sociedades, propósito que cristalizaría en lugares como Santander, Torrelavega, Barreda, Reocín, Heras, Nueva Montaña y Cajo ${ }^{37}$.

Semejantes esfuerzos iban a ser completados, ya en marzo de 1917 , con la puesta en marcha de una nueva iniciativa destinada a reforzar los mecanismos defensivos de la clase asalariada. La misma consistió en la fundación por los trabajadores en metal de un organismo de ámbito provincial bajo el nombre de «Sindicato Obrero Metalúrgico Montañés». Éste aspiraba a encuadrar a todos los empleados del consabido sector productivo en Cantabria sin distinciones de categoría profesional, empresa o población. Con tal fin, los afiliados debían integrarse a través de diferentes secciones locales que estarían coordinadas por un Comité elegido democráticamente en asamblea ${ }^{38}$.

Esta estructura unitaria y centralizada, cuya existencia se basaba en una caja común a todas las colectividades adscritas, iba a proyectarse a lo largo de las semanas posteriores mediante la formalización de distintas secciones por la provincia. Citadas por orden de asentamiento en el Registro General de Asociaciones, esas entidades fueron la de moldeadores y modelistas de Santander, así como las de operarios en hierro y demás metales de El Astillero, Guarnizo, Santander y Torrelavega ${ }^{39}$.

Ahora bien, apenas había entrado en funcionamiento el primer sindicato de industria de Cantabria, cuando quedó en suspenso (al igual que el resto del movimiento obrero de la región) debido a la singular situación creada en el verano de 1917. Ocurrió que, luego de promover numerosos

36 En este sentido, cuando a comienzos de 1916 el Comité Nacional de la UGT volvió a hacer un cómputo de efectivos en todo el país, Cantabria figuraba con 1.730 miembros afectos que se repartían entre 18 secciones (El Socialista, 19-V-1917).

37 De resultas del nacimiento de estas entidades, y una vez deducidas algunas que se disolvieron, UGT contaba en enero de 1917 con 12 secciones y 1.826 federados en Cantabria (Ibid.).

38 El Cantábrico, 3-111-1917.

39 Archivo del Gobierno de Cantabria, «Registro...», libro I, loc. cit. 
mítines y manifestaciones con objeto de protestar tanto por las adversas condiciones socio-económicas en que se hallaba el proletariado como por el corrupto sistema político que padecía España, los máximos dirigentes nacionales de la UGT y el PSOE acordaron responder a la pasividad del Gobierno ante dichos problemas con la convocatoria de una huelga general limitada en todo el país.

Comenzada la huelga el día 13 de agosto como una revolución orientada a democratizar España, las autoridades dispusieron un enorme despliegue de fuerzas de seguridad. Tal prevención no fue óbice, empero, para que la convocatoria tuviese un seguimiento masivo en la mavor parte del Estado. Lejos de constituir una excepción a este panorama preponderante, las zonas industriales y mineras de Cantabria también se sumaron al paro general, siendo de subrayar la dimensión especial que el mismo revistió en Santander, ya que estaba veraneando en ella Alfonso XIII. Junto a esta peculiaridad de la capital, el cese de actividades laborales en la región se significó, además, por algunos incidentes leves, la clausura de las sedes societarias y la realización de infinidad de detenciones (tan sólo en Santander hubo más de 200) ${ }^{40}$.

Tras varios días de tensión, la huelga iba a concluir, como en el resto de España, el 18 de agosto asfixiada por las medidas represivas que había ordenado el Gobierno. Este desenlace, que suponía el fracaso del intento transformador acometido por las organizaciones obreras, comportó un sentimiento de frustración para éstas debido a las consecuencias del mismo. Entre ellas cabe señalar el desmantelamiento temporal de todas las sociedades de resistencia, el procesamiento de muchos líderes societarios, amén de la adopción de represalias en bastantes empresas (públicas y privadas), como sucedió en Cantabria con el despido de no pocos tranviarios, ferroviarios y metalúrgicos ${ }^{41}$.

La intensa convulsión provocada por la huelga de agosto iba a remitir en octubre, circunstancia que impulsó a los gobernantes a levantar, primero, el estado de guerra y a restablecer, luego, las garantías constitucionales. En este ambiente, desde el día 20 fueron reabriéndose las distintas sedes obreras de Cantabria, en un proceso abierto con la de la capital y terminado con la de Cabárceno. Pero el retorno a la normalidad exigía también auxiliar a quienes estaban privados de libertad a causa de

40 El Cantábríco, 13 a 18-VIII-1917; y Fundación Pablo iglesias, AA.VV.-ABA 153-10. Ramos, A., «Movimiento...", loc. cit.

41 Cfr. El Cantábrico, 19-VIII-1917; y Alonso [GonZáleZ], B., El proletariado..., op. cit., pág. 36. 
la represión; por ello, se desarrollaron algunas iniciativas, entre las que sobresalen la adquisición de un crédito de 1.000 pesetas por la Federación Local de Santander con el fin de ayudar a los trabajadores encarcelados o la celebración de diversos actos en favor de una amnistía para los presos políticos y sociales. Aun así, sería preciso esperar a bien entrado el año 1918 para que el ugetismo montañés pudiera acabar de recomponer la estructura defensiva que había ido construyendo en el curso de los decenios precedentes ${ }^{42}$.

\section{CONCLUSIÓN}

Concebido como una necesidad ante el creciente estado de desamparo a que se veían abocados los trabajadores por efecto de la aparición de procesos productivos cada vez más modernos y exigentes, el asociacionismo obrero iba a iniciarse en Cantabria (al igual que en otras zonas de España) a lo largo del siglo XIX. Esta circunstancia, que comenzó materializándose en la fundación de sociedades de socorros mutuos, primero, y de cooperativas de producción y consumo, después, alcanzaría su mejor exponente en la referida región desde la década de los años ochenta con el nacimiento de entidades de resistencia.

Los organismos de este último tipo, integrados por operarios pertenecientes a un mismo oficio dentro de una población, tenían como propósito crear un fondo común con el que hacer frente a los períodos de cese voluntario de la actividad laboral causados por las arbitrariedades de los patronos. Gracias a este procedimiento (cuyo fundamento residía en las aportaciones que realizaban los socios a través de las cuotas) se confiaba en forzar la adopción de acuerdos colectivos que reemplazasen a los tradicionales de carácter individual, en los que se hacía manifiesta la debilidad extrema de los proletarios con respecto a los empresarios.

Habida cuenta de las ventajas de esta novedosa fórmula de asociación, pero también de las limitaciones que evidenciaba (derivadas, en especial, de la adscripción de cada organismo a un único oficio y localidad), no iba a tardar en plantearse la conveniencia de trascender ese reducido ámbito de actuación. Dicho proyecto, analizado durante un congreso obre-

42 Ver El Cantábrico, 8, 19, 21, 25 y 28-X, 3, 8, 25 y 26-XI, 3-XII-1917, así como Archivo Histórico Nacional-Sección Guerra Civil (Salamanca), S-PS Santander 0-141/1, «Libro de actas de las juntas generales celebradas por la Sociedad de Obreros del Gas y la Electricidad de Santander», folio 13 . 
ro que tuvo lugar en Barcelona a mediados de agosto de 1888, se concretó en la creación de la UGT, que aspiraba a aglutinar al mayor número posible de sociedades de resistencia de toda España con vistas a favorecer la mejora de las condiciones laborales del conjunto de la clase asalariada.

Tales directrices, suscritas por colectividades obreras de varios puntos del país, iban a contar, asimismo, con la adhesión de algunas asociaciones defensivas de la capital montañesa desde principios de los años noventa. A ello contribuyó el clima de entusiasmo generado por la Fiesta del Trabajo que, instaurada en 1890, vigorizó al proletariado lo suficiente como para que más de una decena de entidades, siguiendo la pauta trazada por la de empleados de las artes gráficas, formalizasen su ingreso en la UGT, bien a título individual, bien en su calidad de miembros del Centro Obrero de la ciudad.

Esta incipiente efervescencia societaría iba a adquirir la máxima magnitud hasta entonces conocida en suelo cántabro merced a la inauguración, en 1893, de unas amplias instalaciones en la calle de las Animas. El disfrute de las mismas, que pronto se convirtieron en referente básico para la población trabajadora, coincidió, sin embargo, con el inicio de una crisis económica. De resultas de los efectos de ella, el movimiento obrero entró en una fase decadente a consecuencia de la cual se fueron disolviendo casi todas las sociedadies que le configuraban.

La tendencia regresiva así abierta, prolongada por espacio de varios años, iba a terminar en 1898, con motivo de la derrota militar ante Estados Unidos. Fruto del cuestionamiento del orden socio-político vigente a que la misma dio lugar, se produjo un resurgir obrerista. Dentro de Cantabria, semejante revitalización tuvo sus elementos impulsores en las instalaciones de la calle de las Ánimas, en una campaña de propaganda y en la fundación del periódico La Voz del Pueblo. A estos factores habría que añadir, además, el comienzo de una etapa de crecimiento facilitada por la puesta en marcha de un nuevo modelo económico centrado en la explotación minera y el desarrollo de una industria moderna.

Inmerso, pues, en esta coyuntura peculiar, y estimulado por el incremento en el volumen de población asalariada que se estaba registrando, el movimiento obrero montañés iba a conocer durante el tránsito de siglo XIX al Xx un progreso notable. Prueba de ese fenómeno fueron tanto la reorganización y constitución de muchas sociedades de resistencia en Santander como el ingreso de parte de ellas en la UGT. Los avances descritos se completaron, a la vez, con un aumento de la conflictividad laboral, que alcanzó un nivel importante en el marco territorial considerado. 
En medio de esta dinámica expansiva (que estuvo jalonada por diversas mejoras en las condiciones laborales del proletariado), los líderes societarios de la capital cántabra iban a valorar la posibilidad de dotarse de una estructura defensiva más compleja. Este designio se consumó en 1901, con ocasión del nacimiento de la Federación Local de Sociedades obreras, que, ideada con el fin de encuadrar a todas las colectividades de oficio de la ciudad, se vincularía a la UGT, en la confianza de proporcionar así la máxima proyección geográfica a sus actividades.

Al margen de reportar beneficios directos (reducción de la jornada, incremento retributivo y mejor trato en bastantes empresas), debido a la mayor capacidad negociadora que confirió a la clase trabajadora, la Federación Local de Santander iba a coadyuvar también a la difusión del asociacionismo obrero por los núcleos industriales y mineros más relevantes de la provincia. En virtud de este proceso, Cantabria quedaría erigida como uno de los principales enclaves ugetistas de España.

La situación expuesta iba a modificarse, no obstante, entre 1903 y 1905, cuando los intentos anarquistas por menoscabar al socialismo, el inicio de una recesión económica, amén de la pérdida de dos huelgas importantes por los cargadores del muelle de Santander (que integraban la mayor entidad defensiva de la región) confluyeron para provocar la quiebra del entramado societario construido en los años anteriores. Así las cosas, el obrerismo montañés se vio sumido en un estado de abatimiento tal que numerosos patronos estuvieron en condiciones de revocar parte de los logros que hasta entonces habian conseguido sus operarios.

Pese a los esfuerzos de propaganda y captación (sobre todo a través de la Sección Artística) desplegados por los dirigentes obreros de Cantabria el panorama indicado aún iba a perpetuarse durante varios años, hecho que se tradujo en una escasa actividad societaria y en una merma de la conflictividad laboral. Sería necesario aguardar al verano de 1909 para que la gran alteración social causada por los sucesos de la Semana Trágica actuase como acicate de cara a la recuperación. Ésta se fue concretando en la aparición de colectividades de resistencia en diversos puntos que, si bien no se incorporaron en su totalidad a la UGT, quedaron dentro de su ámbito de influencia gracias al fuerte ascendiente ejercido por la Federación Local santanderina.

El rebrote obrerista de esta manera acaecido iba a persistir hasta mediados de 1914, en que la crisis económica originada por el estallido de la 1 Guerra Mundial puso fin al nuevo período de expansión. Luego de un paréntesis regresivo de cerca de dos años, el propio recrudecimiento de los problemas de paro y carestía de la vida que había suscitado la con- 
tienda bélica impulsaría desde 1916 a la clase asalariada a concentrar sus energías en la tarea de robustecer su sistema de defensa. En el caso cántabro, esta aspiración se reflejó tanto en la creación de varias sociedades como, muy especialmente, en la fundación por los obreros del metal del primer sindicato de industria de la provincia.

Aunque la flamante modalidad asociativa se inició con el nacimiento en 1917 del Sindicato Obrero Metalúrgico Montañés (que pretendía agrupar a todos los trabajadores de ese sector sin distinción de categoría profesional, empresa o localidad) los primeros momentos de su existencia iban a estar marcados por la decisión de los máximos responsables ugetistas de promover una huelga general en España al objeto de reclamar la democratización del país. Ello obedeció al fracaso final de dicho conflicto, que, verificado en agosto de aquel año, implicaría no sólo el malogro del propósito perseguido, sino también la interrupción temporal de cualquier actividad obrerista debido a la durísima represión dispuesta por las autoridades del Estado.

De este modo, quedaba en suspenso una experiencia que, surgida tres décadas antes, había tenido como objeto velar por los intereses de la población obrera. Semejante iniciativa, cuyo desarrollo fue posible al amparo de la cobertura dispensada para toda España por la UGT, se significó por un permanente carácter democrático, moderado, negociador y pacífico. El mismo, definido, en un principio, por numerosas entidades de oficio y, después, por el primer sindicato de industria, supuso un cambio considerable en la realidad socio-económica de Cantabria, ya que favoreció la irrupción del proletariado como fuerza emergente. Gracias a ello, los componentes de la mencionada clase alcanzaron importantes mejoras materiales, a la par que pudieron gozar de parte del protagonismo que les correspondía de acuerdo con su amplitud cuantitativa y aportación de conjunto a la sociedad. 